\title{
Evaluating the Effect of EMLA Anesthetic Gel on the Level of Pain upon Probing in Patients with Chronic Periodontitis
}

\author{
Shariatmadarahmadi $\mathbf{R}^{\mathbf{1}^{*}}$, Avadi $\mathbf{M R}^{2}$, Dastani $\mathbf{A}^{\mathbf{3}}$ \\ ${ }^{1}$ Assistant professor,Periodontics Dept,Dental Branch of Tehran, Islamic Azad University, Tehran, Iran \\ ${ }^{2}$ Phd pharmaceutics ,Nanotechnology Dept,School of Pharmacy,Pharmaceutical Sciences Branch,Dental Branch of Tehran, Islamic Azad University, \\ Tehran, Iran \\ ${ }^{3}$ Dentist
}

\begin{tabular}{l}
\hline ARTICLE INFO \\
\hline Article Type \\
Original Article \\
Article History \\
Received: April 2016 \\
Accepted: July 2016 \\
ePublished: Oct 2016 \\
\hline
\end{tabular}

Keywords:

EMLA,

Gel,

Placebo,

Periodontal pocket

\section{ABSTRACT}

Background and aim: Probing is the only reliable method for diagnosing periodontal diseases; however, it is a painful examination. The purpose of this study was evaluation of the effect of EMLA anesthetic gel on the level of pain upon probing in patients with chronic periodontitis referring to the periodontology department of the dental branch of Islamic Azad University of Tehran during 2013-2014.

Materials and methods: This double-blind split mouth clinical trial involved 20 eligible patients. All the teeth in two quadrants of each patient's mouth were randomly selected to be either treated with the anesthetic gel or the placebo and were probed in six points. Afterwards, the level of pain was measured using the VAS ruler. Thirty seconds after applying the gel and probing, the pain was measured again and registered. Results: The levels of pain before and after using the gel were compared using the statistical tests. The levels of pain before and after using the placebo gel were $5.4 \pm 1.8$ and $5.1 \pm 1.8$, respectively and pain variations in this group equaled $0.25 \pm 0.9(\mathrm{P}=0.4)$. The levels of pain before and after using the anesthetic gel were $5.65 \pm 1.7$ and $2.1 \pm 1.2$, respectively. Pain variations in this group equaled $3.55 \pm 1.3$ and this difference was statistically significant $(\mathrm{P}<0.001)$.

Conclusion: The results of the present study showed that EMLA anesthetic gel is effective in reducing the pain upon probing.

Please cite this paper as: Shariatmadarahmadi R, Avadi M , Dastani A.Evaluating the Effect of EMLA Anesthetic Gel on the Level of Pain upon Probing in Patients with Chronic Periodontitis. J Res Dent Maxillofac Sci .2016;1(4):26-31

*Corresponding author: 


\section{Introduction:}

Probing is one of the methods for examination and assessment of periodontal tissues. It is usually performed in six points around each tooth to gather information for thorough and correct evaluation of the oral cavity. In addition, this technique is used for reevaluation of periodontal status and assessment of phase 1 treatments and also for assessment of the amount of stability and progression of periodontal diseases. ${ }^{(1)}$

However, probing is a painful procedure especially in patients with untreated periodontitis. Pain upon probing is a common complication. Probing has been reported as extremely painful in 15 to $77 \%$ of untreated periodontal patients and this pain is mostly related to inflammation of periodontal tissues. ${ }^{(2-4)}$

A study on the histological levels of untreated inflamed periodontal tissues has explained the reason for this pain. In inflamed periodontal tissues, the probe passes the epithelium at the bottom of the periodontal pocket and penetrates the connective tissue that has been infiltrated with inflammatory cells and this causes pain upon probing. When treatment is complete, the probe can no longer penetrate the connective tissue at the bottom of the periodontal pocket. ${ }^{(5)}$

Pain is mainly a body defense mechanism and occurs when body tissues have been injured. Pain is divided to two groups of rapid pain and slow pain with different nervous receptors. All the pain receptors are free nervous terminals distributed in the superficial layers of mucosa and skin and some other tissues such as the periosteum. ${ }^{(6)}$

In topical anesthesia, the signal pathway is blocked at the source and the active agents of anesthetics such as Lidocaine accumulate around the pain receptors and prevent depolarization of the nerve fiber through stabilizing its membrane. ${ }^{(6)}$

Limited practical techniques for pain reduction are available and local anesthetics (gel, ointment and spray) are preferred as they produce less lingering anesthesia. However, they have some limitations including inadequate anesthetic depth, uncontrollable spread of the anesthetic agent, and inadequate duration of anesthesia and difficult guiding of the anesthetic agent to the desired area. ${ }^{(7,8)}$

Topical anesthetics have different states such as gel, ointment, and patch with similar main anesthetic ingredients. ${ }^{(9)}$

Eutectic Mixture of Lidocaine and Prilocaine (EMLA) has found an especial place among topical anesthetics since 1982, ${ }^{(9)}$ and multiple articles have been published to compare its effect with that of other topical anesthetics and in most of them, EMLA has been stated to be more effective than other common anesthetics such as lidocaine ${ }^{(10)}$, benzocaine and lignocaine. ${ }^{(11)}$

EMLA was first used as an emulsion containing lidocaine, prilocaine, Arlatone as emulsifier and Carbopol as volumizing agent. Sodium hydroxide was also used to reach the $\mathrm{pH}$ of 9.6. ${ }^{(12)}$

The melting points of lidocaine and prilocaine are 69 and $37^{\circ} \mathrm{C}$, respectively but the melting point of their mixture is $17^{\circ} \mathrm{C}$, which allows EMLA to be liquid in the oral cavity environment and to get absorbed more easily. ${ }^{(12)}$

During the recent years, EMLA has been mostly used as gel similar to other local anesthetics for easier control and longer duration in the area. ${ }^{(12)}$

As to date no other study in Iran has evaluated the effect of this anesthetic gel on patient's pain upon probing, we decided to evaluate the effect of EMLA anesthetic gel on patients with chronic periodontitis referring to the periodontology department of the dental branch of Islamic Azad University of Tehran during 2013-2014.

\section{Materials and methods:}

This double-blind split mouth clinical trial was performed on the eligible individuals referring to the dental branch of Islamic Azad University of Tehran that were selected according to specific criteria. Only healthy individuals were entered into the present study.

The participants had the following characteristics:

1. The age range of the individuals was between 18 to 55 years.

2. The patients had at least one lateral incisor, one canine, one premolar and one molar in two 
oral quadrants for test and control study and the status of the studied teeth and their counterparts was similar regarding prostheses and restorations.

3 . The patients had moderate to severe generalized chronic periodontitis ( $\mathrm{PD} \geq 4$ and $\mathrm{CAL} \geq 3$ in more than $30 \%$ of the oral cavity).

4. The patients had not received any SRP (Scaling and Root Planing) treatments during the last 6 months.

The exclusion criteria were as follows;

1. Individuals that needed antibiotic prophylaxis before probing.

2. Individuals with mental and chronic pain disorders.

3. Pregnant and lactating women.

4. Patients with idiopathic or congenital methemoglobinemia.

5. Patients with a history of allergy to anesthetic agents.

6. Patients that had received nonsteroidal antiinflammatory drugs during the last three days before the study.

7. Patients with acute periodontal pain, pulpitis, abscess or any other type of acute infection.

After gathering the necessary information, the manner of performing the study was explained to the participants and written informed consents were received.

The anesthetic and placebo gels (with the same taste, color, and odor but without active anesthetic ingredients) were produced by a pharmacist at the food laboratory of Hakim pharmaceutical factory (Tehran, Iran) and were placed in tubes A and B. Expect for the pharmacist, nobody else was aware of the contents of tubes $\mathrm{A}$ and $\mathrm{B}$.

Through coin tossing and randomly, in each patient gel A was used on one side of the mouth and gel B was used on the other side. On each side of the oral cavity, only one quadrant was chosen randomly for study. First, probing was performed in six points around each tooth using Williams probe (Hu-Friedy, USA). Afterwards, the patient's mouth was irrigated with water for 30 seconds and the patient was asked to show the level of pain on a 10 -scale VAS ruler ( 0 to 10). Zero represents no pain and 10 represents the worst pain imaginable. The results were registered in the list designated to each patient. Afterwards, the area was isolated with cotton roll, tongue retractor and suction. $0.5 \mathrm{cc}$ of gel A was poured in a $1 \mathrm{cc}, 30$ gauge insulin syringe. $(0.5$ cc volume had been determined during the pilot study and is the gel volume necessary to fill the periodontal pockets in one quadrant). ${ }^{(19)}$ Then, the gel was entered into each periodontal pocket using the syringe. The gel was not used around central incisors and no probing was performed in this area. After 30 seconds, probing was again performed in six points around each tooth.

After probing, the gel remnants in each quadrant were irrigated with water syringe for $30 \mathrm{sec}-$ onds and the patient was again asked to show the level of pain on the VAS ruler and the results were registered. The same procedure was repeated on the other side of the oral cavity using gel B.

Laboratory stages:

This phase has been performed in cooperation with Hakim pharmaceutical factory.

The ingredients of the anesthetic gel and their percentages in total volume of the gel:

1. Base lidocaine and base prilocaine as active agents, $0.5 \%$.

2. Carbomer 940 (synthalen) as gelling agent, $1 \%$.

3. Propylene glycol as plasticizer, $10 \%$.

4. Ethanol $96 \%$ as solvent for the two active agents, $5 \%$.

5. Tween as wetting agent, which increases the solubility of lidocaine and prilocaine, $1 \%$.

6. Distilled water as major portion of the gel base, $77.6 \%$.

7. Methylparaben as preservative agent (antibacterial), $0.2 \%$.

8. Propylparaben as preservative agent (antifungal), $0.2 \%$.

Method of preparation of EMLA liquid gel:

1. Water was warmed up to $70{ }^{\circ} \mathrm{C}$ and then the preservatives including Methylparaben and Propylparaben were added and solved and the temperature was reduced to $35^{\circ} \mathrm{C}$.

2. Lidocaine and Prilocaine active agents were solved in the minimum amount of alcohol and then propylene glycol was added and was allowed to get mixed completely to create a uni- 
form solution.

3. Carbomer was added to solution 1 and was mixed until it was completely dispersed in the water.

4. Solution 2 was added to solution 3 and was stirred.

5. Triethanolamine was added to solution 4 and was stirred until a uniform gel was obtained. ${ }^{(13)}$

All the mentioned ingredients were used for producing the placebo gel except for lidocaine and prilocaine active agents.

The amount of the produced gel for research purposes has been reported to be 50 grams. The information obtained from each patient was entered in the designated lists and the data were analyzed using T-test and paired T-test. This research has been registered at the Iranian Registry of Clinical Trials (IRCT) with code number of Irct ID: IRCT201409143720N4.

\section{Result:}

This study was performed on 20 patients that met the inclusion criteria (40 samples). The average age of the individuals equaled $47.65 \pm 12.6$ years (minimum age of 18 and maximum age of 55 years) including 10 females and 10 males.

The results of pain measurement upon probing before using the anesthetic and placebo gels and after using them in the two evaluated quadrants are presented in Table 1 which shows that:

The level of pain before using the placebo gel was $5.4 \pm 1.8$ and after using the placebo gel was $5.1 \pm 1.8$ and pain variations in this group equaled $0.25 \pm 0.9$. This difference is not significant $(\mathrm{p}=0.4)$.

The level of pain before using the anesthetic gel was $5.65 \pm 1.7$, while after using the anesthetic gel it equaled $2.1 \pm 1.2$ and pain variations in this group equaled $3.55 \pm 1.3$. This difference is significant $(\mathrm{p}<0.001)$.

The level of primary pain (before using the gel) in the placebo gel group was $5.4 \pm 1.8$, while in the anesthetic gel group this level was $5.65 \pm 1.7$. The difference between these two levels is not significant $(\mathrm{p}=0.4)$. The level of secondary pain (after using the gel) in the pla- cebo group was 5.1 \pm 1.8 and in the anesthetic gel group it was 2.1 \pm 1.2 . The difference is significant $(\mathrm{p}<0.001)$.

Pain variations in the placebo group equaled $0.25 \pm 0.9$, while in the anesthetic gel group the variations equaled $3.55 \pm 1.3$. The difference between these two values is significant $(\mathrm{p}<0.001)$. (Table 1$)$

Table 1- The level of patient's pain based on the evaluated groups of patients with chronic periodontitis

\begin{tabular}{|c|c|c|c|c|}
\hline Level of pain & $\begin{array}{c}\text { Primary } \\
\text { pain }\end{array}$ & $\begin{array}{c}\text { Secondary } \\
\text { pain }\end{array}$ & Variations & $\begin{array}{l}\text { Intra-group } \\
\text { test result }\end{array}$ \\
\hline Placebo gel & $5.4 \pm 1.8$ & $5.1 \pm 1.8$ & $0.25 \pm 0.9$ & $\mathrm{P}=0.4$ \\
\hline $\begin{array}{l}\text { EMLA anesthetic } \\
\text { gel }\end{array}$ & $5.65 \pm 1.7$ & $2.1 \pm 1.2$ & $3.55 \pm 1.3$ & $\mathrm{P}<0.001$ \\
\hline $\begin{array}{l}\text { Inter-group test } \\
\text { result }\end{array}$ & $\mathrm{P}=0.4$ & $\mathrm{P}<0.001$ & $\mathrm{P}<0.001$ & \\
\hline
\end{tabular}

\section{Discussion:}

This was a double-blind split mouth clinical trial. The level of pain reduction upon probing measured by 10 -scale VAS ruler $(10 \mathrm{~cm})$ in the side of the mouth on which the placebo gel was applied equaled $0.25 \pm 0.9$, while in the side of the mouth on which the anesthetic gel was applied it was $3.55 \pm 1.3$ and the results showed that the difference between the two groups is significant. The EMLA anesthetic gel was more effective.

Mishra et al in 2016 compared the effect of lidocaine $10 \%$ anesthetic gel and benzocaine $20 \%$ gel on pain reduction upon probing. They reported that both gels were effective in reducing the pain upon probing in patients with chronic periodontitis. ${ }^{(14)}$

In a study by Winning et al in 2012 on amount of pain upon probing measured by VAS $100 \mathrm{~mm}$ ruler the results showed significant pain reduction after using the anesthetic gel. ${ }^{(15)}$

In another study by Donaldson et al in 1995 regarding the comparison of the effectiveness of EMLA $5 \%$ anesthetic ointment with that of lidocaine 5\% anesthetic gel upon probing, the results showed that EMLA ointment was more effective than lidocaine gel upon probing. ${ }^{(16)}$

In studies by Jeffcoat et al in 2001 ${ }^{(17)}$, Donaldson et al in $2003^{(18)}$ and Magnusson et al in $2003^{(19)}$ with double-blind randomized control-placebo design, an- 
esthetic gel was used for SRP and pain reduction was obvious after using the anesthetic gel in comparison with the placebo. However, the level of pain reduction was lower than that in our study.

There are a number of reasons why the level of pain reduction in these studies was lower than that of ours.

First, parallel groups were evaluated in the three mentioned studies, while the present study used a single group with split mouth design. In parallel groups, factors such as age, gender, previous pain experience, level of literacy and smoking affect the level of pain reported by the patient.

Secondly, pain measurement was done during scaling procedure in the mentioned studies, while in the present study the pain upon probing has been measured. The pain expressed during SRP has two origins: first, gingival tissue and second, dentinal tubules. The anesthetic gel affects the first source but has no effect on the tooth. However, the only source of pain upon probing is the gingiva. Therefore, pain reduction is less in SRP.

Thirdly, periodontal probing causes more pain than SRP because pain upon probing is related to the level of gingival inflammation and in the present study, the patients with chronic periodontitis with $\mathrm{PD} \geq 4$ and $\mathrm{CAL} \geq 3$ that had not received any periodontal treatments during the last 6 months were involved, which shows definite presence of inflammation in these patients. As a result, the gel will have a higher potential for pain reduction upon probing in comparison with SRP. ${ }^{(15,20)}$

A common topic in the pain-related studies is that in the majority of them VAS index has been used as a reference for pain measurement. Although VAS is not a perfect criterion due to confounding variables such as mental state of the patient and subjective assessment of pain by each individual, currently it is a reliable,repeatable and simple method for quantitative pain measurement. ${ }^{(7,8)}$

\section{Conclusion:}

Pain measurement based on VAS index showed the favorable effect of EMLA anesthetic gel on pain reduction upon probing in patients with chronic periodontitis when compared with the placebo gel. It seems that application of this gel can be beneficial to those patients that recall probing as a painful experience.

\section{Acknowledgements:}

We are thankful to those who helped us in this article including the research center of Islamic Azad University, Dental Branch of Tehran.

\section{Conflicts of Interest:}

The authors of this manuscript certify that they have no conflicts of interest regarding this research.

\section{References:}

1.Claffey N.Decision Making in periodontal therapy. J Clin Periodontol 1991;18(6):384-9.

2. van Steenberghe D, Garmyn P, Geers L, Hendrickx E, Maréchal M, Huizar K,et al.Patients' experience of pain and discomfort during instrumentation in the diagnosis and non-surgical treatment of periodontitis. J Periodontol 2004;75(11):1465-70.

3.Al-Ajmix M, Bogle G, Cole R, Rathbun E, Riggs M, Egelberg J.Ability of

examiner to estimate the pain experienced by patients from probing during

initial periodontal examination. J Periodontol 2005;76(6):985-90.

4. Sarlati F, Simdar N, Shariatmadarahmadi R,Shabahangfar MR.Comparative evaluation of immediate effect of root instrumentation with curettes and mini-insert ultrasonic scalers on Clinical Attachment Level.J Res Dentomaxillofac Sci 2016;1(3):38-43.

5.Fowler C, Garrett S ,Cigger M, EgelbergJ. Histologic prob positionin treated and untreated human periodontal tissues. J ClinPeriodontol 1982;9(5):373-85.

6.Oikarinen V J,Ylipaavalniemi P,Evers H,.Pain and temperature sensation related local analgesia . Int J Oral Surg 1975;4(4):151-6.

7.Scott J, Huskisson EG.Graphic representation of pain.pain 1976;2(2):175-84. 
8.Bennett K, Torrance G,Tugwell P.Methodologic challenges in the development of utility measures of health-related quality of life in rheumatoid arthritis . Control Clin Trials 1991;12(4 Suppl):118S-128S.

9 Ehrenström Reiz GM, Reiz SL.EMLA - a eutectic mixture of local anaesthetics for topical anaesthesia. Acta Anaesthesiol Sc and 1982;26(6):596-8.

10.Hassio J, Numminen M, Rosenberg PH, Jokinen T. Topical anaesthesia of gingival mucosa by $5 \%$ eutectic mixture of lignocaine and prilocaine or by $10 \%$ lignocaine spray. Br Joral Maxiloface Surg 1990;28(2):99101.

11.Tulga f,Multu Z . Four type of topical anesthetic agents:evaluation Of clinical effectiveness. J Clin Peditr Dent 1999;23(3):217-20.

12. Munshi AK, Hegde AM,Lath R .Use of EMLA:is it an injection free Alternative? J Clin Pediatr Dent 2001;25(3):215-9.

13. Cavino BG. Pharmacology of Local anesthetic agents. BrJ Anaesth 1986;58(7):701-16.

14. Mishra A, Priyanka M, Pradeep K, Reddy Pathakota K. Comparative Evaluation of Pain Scores during Periodontal Probing with or without Anesthetic Gels. Anesthesiol Res Pract 2016;2016:5768482.

15. Winning L, Polyzois L, Nylund K, Kelly A, Claffey N. A placebo-Controlled Trial to Evaluate an Anesthetic Gel When Probing in Patients With Advanced Periodontitis. J Periodontol 2012;83(12):1492-8.

16. Donaldson D, Meechan JG.A comparison of the effects of EMLA cream and topical 5\% lidocaine on discomfort during gingival probing. Anesth Prog 1995;42(1):7-10.

17. Jeffcoat MK, Geurs NC, Magnusson I, MacNeill SR, Mickels N, Roberts F,et al. Intrapocket anesthesia for scaling and root planing: results of a double-blind multicenter trial using lidocaine prilocaine dental gel. J Periodontol 2001;72(7):895-900.

18. Donaldson D, Gelskey SC, Landry RG, Matthews DC, Sandhu HS. A placebo-controlled multi-centred evaluation of an anaesthetic gel (Oraqix) for periodontal therapy. J Clin Periodontol 2003;30(3):171-5. 19. Magnusson I, Geurs NC, Harris PA, Hefti AF, Mariotti AJ, Mauriello SM,et al. Intrapocket anesthesia for scaling and root planing in pain-sensitive patient. J Periodontol 2003;74(5):597-602.

20. Karadottir H, Lenoir L, Barbierato B, Bogle M, Riggs M, Sigurdsson T,et al. Pain experienced by patients during periodontal maintenance treatment. J Periodontol 2002;73(5):536-42. 